\title{
ESTUDO DA ATIVIDADE ANTIFÚNGICA DE EXTRATOS VEGETAIS DE Azadirachta indica FRENTE A CEPA PADRÃO DE Candida albicans ATCC 10231
}

\author{
Juliana Isa Beraldo ${ }^{1}$ \\ Natália de Oliveira Bernardi² \\ Marisa Meurer ${ }^{2}$ \\ Gustavo Meireles Costa ${ }^{3}$ \\ Vinícius Pereira Arantes ${ }^{3}$
}

\begin{abstract}
BERALDO, J. I.; BERNARDI, N. de O.; MEURER, M.; COSTA, G. M.; ARANTES, V. P. Estudo da atividade antifúngica de extratos vegetais de Azadirachta indica frente a cepa padrão de Candida albicans ATCC 10231. Arq. Cienc. Saúde UNIPAR, Umuarama, v. 19, n. 1, p, 25-30, jan./abr. 2015.
\end{abstract}

\begin{abstract}
RESUMO: Azadirachta indica A. Juss, conhecida popularmente como "Neem" é uma árvore indiana, pertencente à família Meliaceae. Apresenta diferentes propriedades terapêuticas, dentre elas, a atividade antibacteriana, antiparasitária, antifúngica e moluliscida. O objetivo do trabalho foi avaliar a atividade antifúngica do extrato bruto das folhas de $A$. indica frente às cepa padrão de Candida albicans ATCC 10231. Os extratos de $A$. indica foram preparados utilizando o álcool etílico $70 \%$, acetato de etila e hexano como agentes extratores. Para a determinação da CIM (Concentração Inibitória Mínima) dos extratos foram realizadas as técnicas de macrodiluição em tubos e microdiluição em placa empregando a técnica do MABA (Microplate Alamar Blue Assay). Para o extrato bruto produzido com álcool etílico $70 \%$ e hexano, revelaram-se incapazes de inibir a cepa $C$. albicans mesmo na concentração de $2000 \mu \mathrm{g} / \mathrm{mL}$, o extrato a base de acetato de etila foi o único capaz de exercer efeitos inibitórios em C. albicans ATCC 10231 na concentração de $2000 \mu \mathrm{g} / \mathrm{mL}$.
\end{abstract}

PALAVRAS-CHAVE: Azadirachta indica; Microbiologia; Candida albicans; Atividade antifúngica.

\section{STUDY ON THE ANTIFUNGAL ACTIVITY OF VEGETABLE EXTRACTS FROM Azadirachta indica IN FACE TO STANDARD Candida albicans ATCC 10231 STRAIN}

\begin{abstract}
Azadirachta indica A. Juss, popularly known as "Neem", is an Indian tree belonging to the Meliaceae family. It has several therapeutic properties, among them, the antifungal activity. The objective was to evaluate the antifungal activity of the crude extract from the leaves of A.indica in face of the standard Candida albicans ATCC 10231 strains. The extracts of $A$. indica were prepared using $70 \%$ ethanol, ethyl acetate and hexane as the extracting agent. For the determination of the MIC (Minimum Inhibitory Concentration) of the extracts, the techniques of macrodilution in tubes and microdilution on plates were performed, using the MABA (Microplate Alamar Blue Assay) technique. The crude extract produced with $70 \%$ ethanol and hexane proved to be unable to inhibit C. albicans strain even at a concentration of $2000 \mu \mathrm{g} / \mathrm{mL}$, whereas the ethyl acetate extract was the only one able to exert inhibitory effects on C. albicans ATCC 10231 at a concentration of $2000 \mu \mathrm{g} / \mathrm{mL}$.

KEYWORDS: Azadirachta indica; Microbiology; Candida albicans; Antifungal activity.
\end{abstract}

\section{Introdução}

Segundo Carvalho et al. (2007) a Organização Mundial da Saúde (OMS), considera as plantas medicinais como importantes instrumentos da assistência farmacêutica, pautado em comunicados e resoluções, expressa sua posição a respeito da necessidade de valorizar a utilização destes recursos no âmbito sanitário. Destaca-se pela própria OMS que cerca de $70 \%$ a $90 \%$ da população dos países, em vias de desenvolvimento, dependem das plantas medicinais como integrante para o desenvolvimento da atenção primária à saúde. As plantas medicinais são aquelas que possuem tradição de uso na população ou em comunidade, são capazes de prevenir, aliviar ou curar enfermidades.

O Brasil é o país com maior diversidade de plantas do mundo, contando com um número estimado de mais de $20 \%$ do total de espécies do planeta (FARIAS et al., 1994). Segundo Carvalho et al. (2007), cerca de 48\% dos medicamentos empregados na terapêutica clínica advêm, direta ou indiretamente, de produtos naturais, especialmente de plantas medicinais. A demanda pela utilização de plantas medici- nais na cura ou prevenção de doenças, cultivo e/ou o extrativismo torna-se cada vez mais importante. A cura por meio de plantas e derivados constituiu durante muito tempo a base da terapêutica. (DI STASI, 1996; ALVES et al., 2008).

Inúmeras substâncias com atividade antibacterianas foram isoladas ao longo da história, dentre eles os óleos essenciais, os terpenos, triterpenos e flavonoides (DI STASI, 1996; BRASIL, 2002; SUBAPRIYA et al., 2005; SUBRAMANIAN et al., 2005; CORDEIRO et al., 2006). Mediantede vias metabólicas secundárias os vegetais podem produzir alcaloides, flavonoides, isoflavonoides, taninos, cumarinas, glicosídeos, terpenos (CECHINEL FILHO; YUNES, 1998; ARROTEIA et al., 2007). Várias espécies de plantas têm sido pesquisadas em relação a produção dos terpenoides (CANTRELL et al., 2001) e fisalinas (PIETRO et al., 2000; JANUÁRIO et al., 2002).

Azadirachta indica A. juss, Meliaceae conhecida popularmente como "Neem" ou Amargosa, planta indiana, cujas propriedades biológicas são conhecida na literatura científica (ALVES et al., 2006; ALVES et al., 2009, KOONA; BUDIDA, 2011). Dentre seus efeitos biológicos sua

DOI: https://doi.org/10.25110/arqsaude.v19i1.2015.5261

${ }^{1}$ Acadêmicos do programa de iniciação científica e programa de bolsas de iniciação científica (PIC/PIBIC) - curso de farmácia da Universidade Paranaense

- Unipar- Unidade de Paranavaí - Endereço: Avenida Huberto Bruning, 360 - Paranavaí-Pr - Tel: 0xx44-3421-4000

${ }^{2}$ Farmacêuticas e responsáveis técnicas do laboratório de Análises Clínicas da Universidade Paranaense - Unipar/Paranavaí-Pr. Endereço: Avenida Huberto Bruning, 360 - Paranavaí-Pr - Tel: 0xx44-3421-4000

${ }^{3}$ Docentes do curso de farmácia da Universidade Paranaense- Unipar- Unidade de Paranavaí (vinicius@unipar.br) - Endereço: Avenida Senador Souza Naves, 613- CEP:87.650.000 - Centro - Cruzeiro do Sul - Pr - Telefone: 0xx44- 9903-7827 
atividade antibacteriana merece destaque, ações antifúngicas, antiparasitário e repelente. $A$. indica é uma árvore milenar, utilizada há séculos no Oriente como planta medicinal para o tratamento de infecções virais, inflamações, feridas, tratamento da tuberculose, como repelente e bactericida (BISWAS et al., 2002; ATWODI; ATWODI, 2009; BRASIL, 2013). O Neem é uma árvore, cresce bem em países tropicais e subtropicais, pode atingir cerca de 30 metros de altura e 80 $\mathrm{cm}$ de largura, apresenta grande quantidade de folhas sempre verdes, imparipenadas, coloração verde-claro, raízes profundas e pivotante, flores pequenas, brancas, bissexuadas, inflorescências com $25 \mathrm{~cm}$ de comprimento, frutos lisos, glabros, elipsóides (MOSSINI; KEMMELMEIER, 2005).

$A$. indica possui quantidade elevadas de Azadiractina, seu principal metabólito ativo, outros compostos tais como os triterpenoides, geduninas, nimbinm, limonoides, solanina, solanol, solanoacetato-3-dia-acetilsolanina, azadiradion, zaridion,nimbineur e diacetil nimbnim. Esses compostos podem ser encontrados em toda a planta, porém nas folhas e sementes destacam-se por apresentar maior concentração (MOSSINI; KEMMELMEIER, 2005).

Os fitoterápicos deverão ter seus efeitos comprovados para o tratamento de enfermidades. Desta forma, será possível propiciar a formação e pesquisa de novos compostos terapêuticos (FARIAS et al., 1994; SIMÕES et al., 2000).

O desenvolvimento de resistência bacteriana e a velocidade deste fato, é fácil compreender que os microrganismos desenvolvem-se a uma velocidade muito superior à capacidade de produção, isolamento e ou síntese de novos compostos. Portanto, torna-se importante estimular a pesquisa e o estudo de nossa biodiversidade, favorecendo a descoberta de novos compostos, menos tóxicos e menos indutores de resistência.

O gênero Candida sp é constituído por mais de 200 espécies, são patógenos humanos e as espécies C. albicans, C. tropicalis, C. parapsilosis, C. krusei, C. glabrata, merecem destaque. A principal espécie é C. albicans, por ser facilmente isolada e por apresentar maior capacidade de causar enfermidades em humanos (FIDEL, 2002). As espécies do gênero podem colonizar diferentes regiões do corpo humano, tais como a boca, vagina e regiões de dobras de pele. As leveduras do gênero Candida sp são classificadas como imperfeitas, podem ser encontradas na forma de leveduras e hifas. Na condição de levedura, são unicelulares, eucarióticos, morfologia ovoide, cilíndrica, alongada e epiculada com aproximadamente 2 a $8 \mu \mathrm{m}$ de largura e 3 a $14 \mu \mathrm{m}$ de comprimento. Esses microrganismos são gram-positivos, aeróbios, podem crescer ocasionalmente em anaerobiose, são cultivados em meios sólidos, o Ágar Sabouraud é o mais comumente empregado e as colônias são brancas,cremosas e com odor característico. Em relação a C. albicans, a levedura apresenta-se diploide com dimorfismo fúngico invertido, são agentes causais de doenças enquanto estiverem na fase leveduriforme (BARBEDO; SGARBI, 2010).

A patogênese da Candida sp é facilitada por fatores inerentes a sua capacidade de aderência às células do hospedeiro. Podem acometer infecções em pele e mucosas, trato digestivo, vagina, cavidade oral (DARÃES et al. 2005; EL-MAHMOOD; OGBONNA; RAJI, 2010).

A partir do exposto, o objetivo do trabalho foi, determinar o MIC Concentração Mínima Inibitória de extratos vegetais de Azadirachta indica frente a cepa padrão de Candida albicans ATCC 10231.

\section{Material e Método}

\section{Preparo do material vegetal}

O material vegetal foi colhido entre os meses de Abril e Junho de 2012 no Horto de Plantas Medicinais e Toxicológicas da Faculdade de Ciências Farmacêuticas da Unesp / Araraquara-SP. As folhas de A.indica foram transferidas para sacos plásticos, transportadas até o laboratório de Microbiologia da Unipar (Paranavaí-Pr). O material vegetal foi imerso em solução de hipoclorito de sódio a $0,01 \%$ por tempo de $45 \mathrm{~min}$. A secagem foi realizada em estufa a temperatura de $40^{\circ} \mathrm{C}$ por 72 horas, após este período a droga vegetal foi triturada em moinho elétrico, armazenada em frascos âmbar até o momento do uso.

\section{Preparo do extrato vegetal}

Os extratos foram preparados utilizando $100 \mathrm{~g}$ de folhas secas trituradas de $A$. indica para $1000 \mathrm{ml}$ do agente extrator. Para obtenção do extrato, a massa recém-pesada foi transferida para o aparelho de turbólise e submetida à agitação por tempo de 10 e descanso de 5 minutos; o presente ciclo foi repetido por 3 vezes. Após a extração, o produto da turbólise foi filtrado, rotaevaporado e acondicionado em frasco âmbar até o momento de uso. Para produção dos extratos empregou-se álcool etílico 70\%, Hexano (PA) e Acetato de etila (PA).

\section{Cepa Padrão}

A cepa de Candida albicans ATCC 10231 Newprov ${ }^{\circledR}$ empregada neste estudo, foi adquirida comercialmente por meio da Universidade Paranaense-Unipar.

\section{Determinação da atividade antifúngica}

Para determinação da MIC uma suspensão fúngica de C. albicans ATCC 10231 foi preparada, empregando solução fisiológica estéril ( $\mathrm{NaCl}$ 9,0 g/L), estabilidade e turbidez comparada a escala número 1 de Mac-Farland. Paralelamente, foram realizados controles da viabilidade da levedura em estudo, frente à ação do Tween 80 e do antifúngico padrão Anfotericina B $(1 \mathrm{mg} / \mathrm{mL})$, realizados mediante técnica de difusão em meio sólido, utilizando discos de papel de filtro (BAUER et al., 1966). A suspensão de leveduras padrão, foi analisada quanto ao crescimento e contagem em UFC/mL, apresentando normal do microrganismo quando semeado em Ágar Sabouraud.

\section{Macrodiluição em tubos}

Para determinação do MIC foram separados (9) nove tubos de ensaio estéreis, rotulados e dispostos em estante metálica, receberam o volume de $2,5 \mathrm{~mL}$ de Caldo Sabouraud, nos tubos de 1 a 9 respectivamente; adicionou-se ao primeiro tubo $2,5 \mathrm{~mL}$ do extrato padronizado na concentração de $4000 \mu \mathrm{g} / \mathrm{mL}$, a diluição do tubo inicial totaliza-se, portanto, na concentração final em $2000 \mu \mathrm{g} / \mathrm{mL}$. A partir deste mo- 
mento procedeu-se diluição seriada com volume de transferência de $2,5 \mathrm{~mL}$ do tubo 1 (um) até o tubo 6 (seis) até atingir concentração de $62,5 \mu \mathrm{g} / \mathrm{mL}$ e descartado $2,5 \mathrm{~mL}$. O tubo de número 7 (sete) recebeu apenas caldo Mueller-Hinton, caracterizando o controle de meio, o oitavo tubo foi considerado controle do extrato e o 9 (nono) tubo foi rotulado como controle de antifúngico padrão, recebendo Anfotericina B na concentração de $1,0 \mathrm{mg} / \mathrm{mL}$. Na sequência foi adicionado em cada tubo $0,05 \%$ do volume da suspensão fúngica padronizada. O microrganismo foi incubado a $37 \pm 2{ }^{\circ} \mathrm{C}$ por 24 horas e após este período a leitura foi realizada.

Para determinação da atividade antifúngica, o MIC foi considerado como a menor concentração capaz de inibir o crescimento fúngico em tubos e a sua correspondente leitura em placas de cultura empregando Agar Sabouraud.

\section{Microdiluição em placa}

O trabalho foi realizado em triplicata, utilizando o método de microdiluição em microplaca contendo 96 poços, seguindo de perto recomendações padronizadas por Franzblau (1998) e adaptações segundo o Clinical and Laboratory Standards Institute (CLSI).

Para a realização da técnica de microdiluição pela metodologia do MABA (Microplate Alamar Blue Assay), foi utilizada placa estéril de 96 orifícios. Nas colunas 1 e 12 em linhas de $\mathrm{A}$ a $\mathrm{H}$ foram adicionados $200 \mu \mathrm{L}$ de água destilada estéril, perfazendo a necessidade de evitar provável evaporação dos compostos a serem testados.

Os orificios presentes nas linhas de A a D da coluna 11 receberam $200 \mu \mathrm{L}$ de caldo Mueller-Hinton, os orifícios correspondentes de $\mathrm{E}$ a $\mathrm{H}$ da coluna 11 receberam $100 \mu \mathrm{L}$ de caldo Mueller-Hinton. Os orifícios correspondentes da linha A de colunas de 2 a 10 receberam $150 \mu \mathrm{L}$ de meio caldo Mueller-Hinton e os de linha B a H referentes a coluna 2 a 10, receberam $100 \mu \mathrm{L}$ de caldo Mueller-Hinton.

Foram então adicionados os extratos diluídos a serem testados. Todos os extratos foram diluídos para que estivessem na concentração inicial de $16.000 \mu \mathrm{g} / \mathrm{ml}$. A linha A e B da microplaca e colunas de 2 a 10, procede-se nova diluição e todos os extratos partiram da diluição de $4.000 \mu \mathrm{g} /$ $\mathrm{ml}$ (linha A); $4.000 \mu \mathrm{g} / \mathrm{ml}$ (linha B); $2.000 \mu \mathrm{g} / \mathrm{ml}$ (linha C); $1.000 \mu \mathrm{g} / \mathrm{ml}$ (linha D); $500 \mu \mathrm{g} / \mathrm{ml}$ (linha E); $250 \mu \mathrm{g} / \mathrm{ml}$ (linha F); $125 \mu \mathrm{g} / \mathrm{ml}$ (linha G); $62.5 \mu \mathrm{g} / \mathrm{ml}$ (linha $\mathrm{H}$ ).

Os orifícios de coluna 2 a 10 da linha A receberam $50 \mu \mathrm{L}$ da diluição de $16.000 \mu \mathrm{g} / \mathrm{ml}$. Os orifícios de linhas B referentes às colunas de 2 a 9 receberam $100 \mu \mathrm{L}$ de extrato e a coluna 10 a droga padrão (Anfotericina $B$ na concentração de $8 \mu \mathrm{g} / \mathrm{mL}$ ). Após a homogeneização da linha $\mathrm{B}$, procede à diluição de linha $\mathrm{B}$ a $\mathrm{H}$ de colunas de 2 a 10, ao final desprezar volume de $100 \mu \mathrm{l}$.

Ao final ser adicionado a suspensão bacilar diluída 1:25 referente a escala n. 1 de MacFarland, realizada após protocolo de obtenção da suspensão bacilar. Os orifícios de colunas de 2 a 10 e linhas de $\mathrm{B}$ a $\mathrm{H}$ receberam volume de 100 $\mu 1$ de suspensão de leveduras, os orifícios das linhas $\mathrm{E}$ a H, referentes à coluna 11 receberam $100 \mu \mathrm{l}$ da suspensão de leveduras, com o intuito de ser controle positivo para bactérias. As placas então foram seladas com filme de polietileno e incubadas em estufa de crescimento aeróbio a temperatura de $37^{\circ} \mathrm{C}$, por período de $24 / 48$ horas de incubação os orifícios A -11 e E-11, receberam $25 \mu \mathrm{l}$ de solução reveladora de Alamar Blue na proporção 1:1 e solução de Tween 80 a $10 \%$ para a cepa de $C$. albicans. As placas então foram reincubadas por 24 horas a $37^{\circ} \mathrm{C}$. A presença de cor rósea indica crescimento microbiano e a presença de coloração azul, indica ausência de crescimento microbiano, para as cores intermediárias as placas foram reincubadas por mais 24 horas.

\section{Resultados}

Para o presente estudo foi aplicada a metodologia de microdiluição em placa, com a finalidade de avaliação antifúngica, empregando revelador crescimento MTT como teste padrão ouro. Os resultados obtidos foram comparados a técnica de macrodiluição. Os testes realizados foram avaliados em triplicata, destinando maior padrão de confiabilidade. Os extratos de $A$. indica foram testados contra cepa padrão de C. albicans ATCC 10231.

Tabela 1: Atividade antifúngica do extrato vegetal de $A$. indica produzido com agente extrator: Etanol (PA).

\begin{tabular}{|c|c|c|c|}
\hline Microrganismo & $\begin{array}{c}\text { Diluições em } \mu \mathrm{g} / \\
\mathrm{mL}\end{array}$ & MIC & $\begin{array}{c}\text { Controle de Crescimento de 103- } \\
\text { 104UFC/mL }\end{array}$ \\
\hline \multirow[t]{6}{*}{ Cepa padrão C. albicans ATCC 10231} & 2000 & Não Observado & $\mathrm{C}+$ \\
\hline & 1000 & Não Observado & $\mathrm{C}+$ \\
\hline & 500 & Não Observado & $\mathrm{C}+$ \\
\hline & 250 & Não Observado & $\mathrm{C}+$ \\
\hline & 125 & Não Observado & $\mathrm{C}+$ \\
\hline & 62,5 & Não Observado & $\mathrm{C}+$ \\
\hline
\end{tabular}

Não observado $=$ crescimento normal; Observado $=$ efeito inibitório exercido pelo extrato; $\mathrm{C}+$ crescimento normal frente ao extrato; $\mathrm{C}$ - crescimento inibido quando exposto ao extrato.

A fração etanólica do extrato de $A$. indica não apresentou efeito antifúngico, tendo visto que para determinações consideráveis e aceitas como padrão ouro para os MICs de extratos brutos, o ideal é que os resultados sejam inferiores a $250 \mu \mathrm{g} / \mathrm{mL}$. 
Tabela 2: Atividade antifúngica do extrato vegetal de $A$. indica produzido com agente extrator: Acetato de etila (PA)

\begin{tabular}{cccc} 
Microrganismo & $\begin{array}{c}\text { Diluições em } \boldsymbol{\mu g} / \\
\mathbf{~ m L}\end{array}$ & MIC & $\begin{array}{c}\text { Controle de Crescimento de 103- } \\
\mathbf{1 0 4 U F C / m L}\end{array}$ \\
Cepa padrão C. albicans ATCC 10231 & 2000 & Observado & $\mathrm{C}$ - \\
& 1000 & Não Observado & $\mathrm{C}+$ \\
$\mathrm{C}+$ & Não Observado & $\mathrm{C}+$ \\
& 500 & Não Observado & $\mathrm{C}+$ \\
\hline
\end{tabular}

*Não observado= crescimento normal; Observado= efeito inibitório exercido pelo extrato; C+ crescimento normal frente ao extrato; Ccrescimento inibido quando exposto ao extrato.

Para as determinações antifúngicas em que o agente extrator foi Acetato de etila, detectou-se MIC discreto de $2000 \mu \mathrm{g} / \mathrm{mL}$, conforme apresentado neste trabalho, foi possível evidenciar que exibe-se o mínimo de atividade antifúngi- ca entre o extrato em teste e C.albicans ATCC 10231, porém a concentração de $2000 \mu \mathrm{g} / \mathrm{mL}$ é muito elevada para as faixas de corte dentre as substâncias com alguma atividade antibacteriana e ou antifúngica.

Tabela 3: Atividade antifúngica do extrato vegetal de $A$. indica produzido com agente extrator: Hexano (PA)

\begin{tabular}{|c|c|c|c|}
\hline Microrganismo & $\begin{array}{c}\text { Diluições em } \mu \mathrm{g} / \\
\mathrm{mL}\end{array}$ & MIC & $\begin{array}{l}\text { Controle de Crescimento de } 103- \\
\text { 104UFC/Ml }\end{array}$ \\
\hline \multirow[t]{6}{*}{ Cepa padrão C. albicans ATCC 10231} & 2000 & Não Observado & $\mathrm{C}+$ \\
\hline & 1000 & Não Observado & $\mathrm{C}+$ \\
\hline & 500 & Não Observado & $\mathrm{C}+$ \\
\hline & 250 & Não Observado & $\mathrm{C}+$ \\
\hline & 125 & Não Observado & $\mathrm{C}+$ \\
\hline & 62,5 & Não Observado & $\mathrm{C}+$ \\
\hline
\end{tabular}

*Não observado= crescimento normal; Observado= efeito inibitório exercido pelo extrato; C+ crescimento normal frente ao extrato; Ccrescimento inibido quando exposto ao extrato.

As frações obtidas com hexano, acetato de etila e etanol, mesmo apresentando diferenças de polaridade, os MICs apresentados foram muito semelhantes, reforçando a ideia que nestas condições e envolvendo estes agentes extratores, não foram obtidos resultados significativos. Os resultados comparados entre os testes em microplacas e aqueles realizados em tubos, não apresentaram diferenças.

Portanto, os MICs apresentados são muito discretos, destacando levemente a inibição a $2000 \mu \mathrm{g} / \mathrm{mL}$ empregando acetato de etila.

\section{Discussão}

Um recurso de sucesso esperado para a descoberta de novos fármacos antifúngicos e com menores efeitos indesejáveis, é sem dúvida a investigação de plantas medicinais, baseando-se na medicina popular, regional e com evidências clínicas. Porém, a melhor forma de aumenta as chances de sucesso está concentrada na necessidade de cura, custo e baixos índices de toxicidade da planta. Desta forma, emprega-se A.indica, planta milenar e com inúmeros atributos clínicos que elegem como necessário o conhecimento mais aprofundado de seus feitos. Neste trabalho destaca-se os estudos antifúngicos frente a cepa de C. albicans, importante de infecções em humanos e animais.

Em estudo realizado por Santos et al. (2005) ao empregar extratos alcoólicos de nem (Azadirachta indica), pode-se comprovar que para testes In Vitro empregando Candida sp como microrganismos teste, os resultados não foram promissores, o que permite a interpretar que o microrganismo apresenta-se resistente ao uso deste extrato nas condições preconizadas pelo autor e sua metodologia empregada. Segundo Pereira et al (2009) em estudo empregando extrato etanólico de Azadirachta indica para avaliação de atividade antifúngica de isolados clínicos de Candida sp proveniente de mastite bovina, também não revelou

ação descritiva como antifúngico, tendo visto que os MICs apresentados foram insatisfatórios. Os resultados se assemelham aos apresentados neste trabalho, pois para estudos empregando o etanol como extrator, os efeitos de MIC não são promissores. Outros autores ainda reafirmam a baixa ação de extratos etanólicos de neem frente a fungos tais como (ARROTEIA; KEMMELMEIER; MACHINSKI, 2007).

Outros estudos também expressam a baixa ou nenhuma atividade do extrato de A.indica frente a cepas de C.albicans, como o estudo realizado por Menezes et al (2009), em que se empregaram várias plantas da região amazônica e $A$. indica, comparando seus efeitos inibitórios.

No entanto, a literatura revela alguns estudos tais como: Darães et al (2005) que descrevem ter verificado suscetibilidade de C.albicans frente a extratos aquosos e alcoólicos de "Neem". Também cabe destcar estudos de Mossini (2006), nas quais os extratos alcoólicos de Azadirachta indica foram ativos contra uma série de dermatófitos tais como Trichophyton rubrum, T. mentagrophytes, T. violaceum, Microsporum nanum, Epidermophyton flocosum, destacando que $A$. indica possui atividade antifúngica e precisa ser analisado em outras constantes metodológicas e de concen- 
tração, quando por sua vez o intuito for de empregar testes envolvendo extratos e fungos de interesse clínico. Em estudo realizado por Arieira et al (2010) ao empregar $A$. indica em estudo para controle do fungo Colletotrichum acutatum em morangueiro foi possível comprovar uma melhora clínica da planta e menor incidência dos efeitos deletérios causados pelo fungo. O fungo em questão é responsável pelo aparecimento da flor preta no morangueiro, considerada a principal doença neste vegetal decorrendo em comprometimento de flores e frutos.

Cabe destacar que diferentes épocas do ano, hora de coleta, armazenamento, forma de preparo do extrato e metodologias distintas, pode-se revelar resultados discutíveis entre as diferentes atividades do extrato etanólico do Neem. Para algumas espécies, é possível determinar efeitos expressivos de MIC frente a C. albicans, como por exemplo nos estudos realizados por Costa (2013), em que espécies de Piper diospyrifolium apresentaram boa atividade. No mesmo estudo ao empregar Piper hispidum obtiveram atividade antibacteriana contra S. aureus e B. subtilis com CIM de 62,5 e 7,8 $\mu \mathrm{g} / \mathrm{ml} \mathrm{e}$ antifungica contra $C$. albicans, $C$. tropicalis e $C$ parapsilosis com CIM 62,5, 15,6 e 15,6 $\mu \mathrm{g} / \mathrm{ml}$ respectivamente.

Para estudos com Aspergillus Niger realizado por Souza (2009), no qual se empregou extrato aquoso de $A$. indica frente a cepas do fungo, pode-se comprovar a existência de efeito inibitório do crescimento micelial. Destacando mais uma vez a necessidade de outros estudos que possam explorar melhor o extrato aquoso e etanólico de nem, frente a gêneros e espécies de fungos de interesse clínico.

No presente estudo as concentrações do extrato hexânico foram reveladoras de baixa ou nenhuma atividade antifúngica, apenas o extrato produzido com acetato de etila demonstrou leve efeito antifúngico e que por ventura possa ser empregado em outras metodologias de estudo com a finalidade de explorar melhor o efeito demonstrado.

\section{Conclusão}

Conclui-se que apenas o extrato a base de acetato de etila apresenta discreto efeito antifúngico, apresentando MIC de $2000 \mu \mathrm{g} / \mathrm{mL}$ Para os extratos a base de hexano e álcool etílico 70\%, os MICs são menos expressivos, destacando que mesmo empregando a máxima concentração disponível, os efeitos não foram significativos. Entretanto, avaliações farmacológicas mais abrangentes deverão ser desenvolvidas, considerando a dinâmica do corpo humano como um todo e o emprego de outras metodologias comparativas e o uso de outros agentes extratores.

\section{Referências:}

ALVES, P. M. et al. Atividade antifúngica do extrato de Psidium guajava Linn. (Goiabeira) sobre leveduras do gênero Candida da cavidade oral: uma avaliação In vitro.

Revista Brasileira de Farmacognosia, v. 16, n. 2, 192-196 abr./jun. 2006.

ALVES, D. P. et al. Avaliação da atividade antibacteriana de extratos brutos de Miconia fallax pelo método da microdiluição em caldo. Revista da Sociedade de Química, FURB, Novembro de 2008.
ALVES, D. P. et al. Chromatiographic evalution ande antimicrobial activity of neem (Azadirachta indica A.juss., Meliaceae) leaves hydroalcoholic extracts. Revista Bras. de Farmacognosia. v. 19, n. 2, p. 510-515, 2009.

ARIEIRA, C. R. D. et al. Atividade de óleo de Eucalyptus citriodora e Azadirachta indica no controle de Colletotrichum acutatum em morangueiro. Summa Phytopathol., Botucatu, v. 36, n. 3, p. 228-232, 2010.

ARROTEIA, C. C.; KEMMELMEIER, C.; MACHINSKI, J. M. Efeito dos Extratos aquoso e oleoso de Nim [Azadirachta indica A. Juss (Meliaceae)] na Produção de patulina em maçãs contaminadas por Penicillium expansum. Cienc. Rural, v. 37, n. 6, p. 1518-1523, 2007.

ATAWODI, S. E.; ATAWODI, J. C. Azadirachta indica (neem): a plant of multiple biological and pharmacological activities. Rev. Phytochem. v. 8, p. 601-620, 2009.

BAUER, A. W. et al. Antibiotic susceptibility testing by a standardized single disk method. Am J Clin Pathol. 1966 Apr; 45(4): 493-6.

BARBEDO, L. S.; SGARBI, D. B. G. Candidíase. J. bras. doenças sex. transmissíveis., v. 22, n. 1, p. 22-38, 2010.

BISWAS, K. et al. Biological activites and medicinal properties of neem (Azadirachta indica). Current Science, v. 82, n. 11, 1336-1345, 2002.

BRASIL. Ministério da Saúde. Secretaria de Políticas de Saúde. Departamento de Atenção Básica. Manual técnico para o controle da tuberculose. Brasília, 2002, 64 p. (Cadernos de Atenção Básica no 6. série A. Normas e Manuais Técnicos, n. 148).

BRASIL, R. B. Aspectos botânicos, usos tradicionais e potencialidades da Azadirachta indica (NEEM). Enciclopédia Biosfera, Centro científico conhecerGoiânia,v. 9, n. 17, p. 3254, 2013.

CANTRELL, C. L.; FRANZBLAU, S. G.; FISCHER, N. H. Antimycobacterial plant terpenoids. Planta Med., v. 67, p. 1-10, 2001.

CARVALHO, A. C. B. et al. Aspectos da legislação no controle de medicamentos fitoterápicos. T \&C Amazônia, Ano v, n. 11, 2007.

CECHINEL FILHO,V.; YUNES, R. A. Estratégias para a obtenção de compostos farmacologicamente ativos a partir de plantas medicinais. Conceitos sobre modificação estrutural para otimização da atividade. Quim. Nova, v. 21, n. 1, p.99-105, 1998.

CORDEIRO, C. H. G. et al. Análise Farmacognóstica e atividade antibacteriana de extratos vegetais empregados em formulação para a higiene bucal. Revista Bras. Ciências Farmac, v. 42, n. 3, p. 395-404, 2006. 
COSTA, G. M. Avaliação da atividade antimicrobiana de plantas medicinais. Dissertação de mestrado - UEM/2013/ Maringá. 73 fl. 2013.

DARÃES, G. V. et al. Suscetibilidade de Candica albicans a extratos de Azadirachta indica (nim). Braz. Oral. Res. São Paulo, v. 4, p. 12-17, 2005.

DI STASI, L. C. Plantas medicinais:arte e ciência. Um guia de estudo inter-disciplinar. São Paulo: Unesp, 1996, p. 230 .

EL-MAHMOOD, A. M.; OGBONNA, O. B.; RAJI, M. The antibacterial activity of Azadarichta indica (neem) seeds extracts against bacterial pathogens associated with eye and ear infections. Journal of Medicinal Plants Research v. 4, n. 14 , p. $1414-1421,2010$.

FARIAS, M. R. et al. Espécies vegetais empregadas na produção de fitoterápicos em Santa Catarina. In: Simpósio de plantas Medicinais do Brasil, 12, 1994, Fortaleza, Anais. Fortaleza, 1994, p. 125.

FIDEL JR, P. L. Distinct protective host defenses against oral and vaginal candidiasis. Med Mycol. 2002; 40 (4): $359-75$.

FRANZBLAU, S. G. et al. Rapid, low-technologiy MIC determination with clinical Mycobacterium tuberculosis isolates by using the MicroplateAlamar Blue Assay. J. Clin. Microbiol. v. 32, n. 2, p. 362-366, 1998.

JANUÁRIO, A. H. et al. Antimycobacterial physalins from Physalis angulata L. Phytother. Res., v. 16, n. 5, p. 445448, 2002.

KOONA, S.; BUDIDA. S. Antibacterial Potential of the Extracts of the Leaves of Azadirachta indica Linn. Not. Sci. Biol, v. 3, n. 1, p. 65-69, 2011.

MENEZES, T. O. A. et al. Avaliação in vitro da atividade antifúngica de óleos essenciais e extratos de plantas da região amazônica sobre cepas de Candida albicans. Revista de Odontologia da Unesp. v. 38, n. 3, p. 184-191, 2009.

MOSSINI, S. A. G.; KEMMELMEIER, C. A árvore Nim (Azadirachta indica. A. Juss.): múltiplos usos. Acta Farmaceutica Bonaerense, Buenos Aires, v. 24, n. 1, p. 139-148, 2005.

MOSSINI, S. A. G. Efeitos de extratos de Azadirachta indica A. Juss (Meliaceae) na produção de micotoxinas e na morfologia de fungos. Maringá 49p. Tese de Doutorado em Ciências Biológicas - Universidade Estadual Maringá. 2006.

PEREIRA, V. A. Atividade anti-fúngica do neem e jurempreta sobre cepas de Candida spp isolados de vacas com mastite subclínica no estado de Pernambuco. Revista Brasileira Farmacognosia e Bras. Journal Pharmacog. vol .19, n. 4, out./dez. 2009.
PIETRO, R. C. L. R. et al. In vitro antimycobacterial activities of Physalis angulata L. Phytomedicine, v. 7, n. 4, p. 335-338, 2000.

SANTOS, V. R. Susceptibilidade de Candida albicans a extratos Azadirachta indica (neem). XXII Reunião Anual da Sociedade Brasileira de pesquisa Odontológica. Águas de Lindóia-SP-Brasil.2005.

SIMÕES, M. O. et al. Farmacognosia: da planta ao medicamento. Porto Alegre/Florianópolis: 2 ed. editora UFRGS/UFSC, 2000.

\section{SOUZA,A.G.F.,ARAÚJO,G.NASCIMENTO,L.C.}

Atividade antifúngica de extratos de alho e capim santo sobre o desenolvimento de Fusarium proliferatum isolado de grãos de milho. Fitopatologia brasileira. V.32,n.6,p.465-471,2007.

SUBAPRIYA, R.; BHUVANESWAR, V.; NAGINI, S. Ethanolic Neem (Azadirachta indica) Leaf Extract Induces Apoptosis in the Hamster Buccal Pouch Carcinogenesis Model by Modulation of Bcl-2, Bim, Caspase 8 and Caspase 3. Asian. Pacific. Journal. of Cancer. Prevention, v. 6, p. 515-520, 2005.

SUBRAMANIAN, S. K.; SISWOMIHARDJO, W.; SUNRINTYAS, S. The effect of different concentrations of Neem (Azadiracthaindica) leaves extract on the inhibition of Streptococcus mutans (In vitro). Maj. Ked. Gigi. (Dent. J.), vol. 38. n. 4, p. 176-179, 2005.

Recebido: 29/05/2014 Aceito: 04/02/2015 